\title{
AGRONEGÓCIO E AGROTÓXICOS: IMPACTOS À SAÚDE DOS TRABALHADORES AGRÍCOLAS NO NORDESTE BRASILEIRO
}

\author{
AGRIBUSINESS AND PESTICIDES: IMPACTS ON THE HEALTH OF AGRICULTURAL WORKERS IN \\ NORTHEASTERN BRAZIL
}

\section{AGRONEGOCIO Y AGROTÓXICOS: IMPACTOS SOBRE LA SALUD DE LOS TRABAJADORES AGRÍCOLAS EN EL NORDESTE BRASILEÑO}

\author{
Isabelle Maria Mendes de Araújo ${ }^{1}$ \\ Ângelo Giuseppe Roncalli da Costa Oliveira ${ }^{2}$
}

Resumo Ao considerar o contexto brasileiro de aumento da produtividade agrícola associado às monoculturas, ao agronegócio e ao uso intensivo de agrotóxicos, diversas externalidades negativas emergem como impactos socioambientais e à saúde pública. O objetivo deste artigo é discutir o fortalecimento do agronegócio no país, compreendendo sua construção como um modelo histórico de modernização em expansão em todo o território brasileiro e crescente no Nordeste. Além disso, discorrer sobre a questão dos agrotóxicos e a saúde, correlacionando-os aos casos de intoxicação humana. Para tal, desenvolvemos uma análise do modelo de modernização ancorado no tripé agronegócio, transgenia e agrotóxicos, e discutimos os casos de intoxicações por agrotóxicos, via usos agrícola e doméstico, mediante sistematização do banco de dados do Sistema Nacional de Informações Toxicofarmacológicas, entre os anos de 1999 e 2011, no Nordeste. Observamos que nos últimos anos o agronegócio se fortalece e o número de casos de intoxicação por agrotóxicos cresce, com destaque para a região Nordeste, que apresenta as maiores taxas de letalidade de intoxicação por agrotóxicos no Brasil, afetando majoritariamente os trabalhadores agrícolas.

Palavras-chave intoxicação; letalidade; agroindústria; trabalhadores rurais.
Abstract When considering the Brazilian context of increasing agricultural productivity associated with monocultures, agribusiness, and the intensive use of pesticides, various negative externalities emerge as having social and environmental impact and affecting public health. The purpose of this article is to discuss the strengthening of agribusiness in Brazil, including its construction as a historical model of modernization expanding nationwide and growing in the Northeast. It also aims to address the issue of pesticides and health, correlating them to cases of human poisoning. To this end, we analyzed the modernization model anchored on the agribusiness, transgenics, and pesticides tripod, and discussed the cases of pesticide poisoning, via agricultural and domestic uses, through the systematization of National Toxicopharmacological Information System database between the years of 1999 and 2011 in the Northeast. We note that in recent years, agribusiness has strengthened itself and the number of pesticide poisoning cases have grown, especially in the Northeast, which has the highest rates of mortality caused by pesticide poisoning in Brazil, mainly affecting farm workers.

Keywords intoxication; lethality; agribusiness; rural workers. 


\section{Introdução}

O atual modelo de desenvolvimento econômico agrário brasileiro e seus processos de produção para o comércio de agroexportação, baseados no crescimento e na globalização da economia mundial, vêm sendo criticados pelas ameaças à sustentabilidade ambiental e sanitária, associadas às iniquidades sociais que vulnerabilizam diferentes territórios e populações, especialmente trabalhadores e moradores de áreas afetadas, grupos indígenas, quilombolas, extrativistas, agricultores familiares e populações urbanas (Porto e Soares, 2012).

Apesar do aumento da capacidade de geração de oferta de alimentos no Brasil e no mundo, é importante salientar que o aumento da produtividade agrícola, associado às monoculturas e ao agronegócio de exportação, tem sido responsável por inúmeros impactos socioambientais e à saúde pública, tais como: a concentração de terras, renda e poder político em grandes produtores; o desemprego; a migração campo-cidade; e o não atendimento às demandas de segurança e à soberania alimentar dos países. No caso de agronegócio de exportação, são produzidas mercadorias agrícolas que não são alimentos (caso dos biocombustíveis, como o etanol, ou a plantação de árvores para produção de celulose e uso em siderúrgicas etc.) ou são exportadas como commodities para os países mais ricos, como a soja, o milho. Some-se a isso o uso intensivo de agroquímicos, em especial os agrotóxicos, e formam-se as marcas da 'modernização agrícola' brasileira, que repercute diretamente sobre a saúde dos trabalhadores agrícolas e consumidores de alimentos contaminados.

Segundo Santos e Chauí (2013), a superexploração do trabalho e a superexploração dos recursos naturais se amalgamam na abordagem histórico-concreta do agronegócio brasileiro. Um processo de caráter altamente concentrador da propriedade e da renda fundiária para responder a pressões externas por ajustamento das transações de mercadorias e serviços.

No atual estágio de nossa dependência externa, esse modelo apela para a superexploração de recursos naturais, a concentração fundiária e o 'descarte' de populações campesinas, de forma a suprir, com produtos primários exportáveis, o déficit da indústria e de serviços e responder ao enorme desequilíbrio econômico externo (Delgado, 2012a).

O modelo hegemônico do agronegócio está associado ao uso intensivo de agrotóxicos, gerando diversas externalidades negativas - ou seja, impactos sociais, ambientais e sanitários que não são incorporados pela cadeia produtiva e são pagos pela sociedade como um todo por meio de gastos públicos - e, mais importante, ocasionando doenças e mortes que poderiam ser evitadas (Porto e Soares, 2012). Traduzidos em números, são a cada ano, no mundo, pelo menos um milhão de pessoas intoxicadas por pesticidas, das 
quais entre três mil e vinte mil são levadas a óbito (Soares e Porto, 2007). Esse cenário ainda é pior em países periféricos e semiperiféricos, onde ocorrem pelo menos metade dessas intoxicações e $75 \%$ dessas mortes, tendo em vista o nível educacional associado aos poucos cuidados com o uso, assim como a regulamentação e os métodos de controle, frequentemente negligentes ou inexistentes (Carneiro et al., 2015).

Nessa perspectiva, o Nordeste do Brasil compõe atualmente uma das regiões brasileiras que mais tem sofrido com a expansão e a ocupação de lugares voltados para a produção de uma agropecuária atenta aos ditames do agronegócio (Bezerra, 2008). Assim, pretendemos discutir a questão do agronegócio no Brasil e as repercussões do uso de agrotóxicos na saúde da população, principalmente entre os trabalhadores agrícolas, no Nordeste brasileiro.

\section{Agronegócio e agrotóxicos: modelo de veneno}

A palavra 'agronegócio' tem origem na década de 1990 e representou uma construção ideológica para consolidar uma imagem de um novo modelo de desenvolvimento da agricultura: sofisticado, eficiente, produtivo. Historicamente o termo expressa um modelo que vem dominando a produção agrícola no país: grandes propriedades de terras que produzem para exportação, com modificações e adaptações em suas diferentes fases, intensificando a exploração da terra e do homem (Carneiro et al., 2015).

A inserção brasileira na divisão internacional do trabalho, segundo Delgado (2012b), se dá como provedora de bens primários no comércio mundial, com um modelo primário e exportador, dentro de um ciclo econômico mundial liderado pela China. Desde o segundo governo de Fernando Henrique Cardoso (FHC), rearticula-se o processo de modernização técnica da agropecuária impulsionado pelos militares no período de 1960-1970. Reestrutura-se a aliança das cadeias agroindustriais, da grande propriedade fundiária e do Estado, promovendo um estilo de expansão agrícola sem reforma agrária social. Esse pacto se dá com a inserção no mercado externo e com um projeto de hegemonia política que se inicia nos anos 1990, amplia-se e se intensifica no primeiro e segundo governos Lula, e continua no governo Dilma, acompanhado pelo poder midiático, parlamentar e acadêmico que enreda o Estado brasileiro em um conjunto de políticas de acumulação de capital pelo setor primário, com captura de recursos primários e renda fundiária ligadas ao setor externo (Delgado, 2012a).

As políticas econômicas se mostram mais voltadas para atender aos interesses de setores de produção do que às necessidades fundamentais dos consumidores. Nesse sentido, a produção de alimentos está direcionada a manter a alta produtividade e lucro numa lógica que atenda às exigências 
de mercado. Desse modo, é figurado o processo de modernização da agricultura como conservador, excludente e doloroso: Conservador porque não provocou mudanças na estrutura fundiária, tornando a posse da terra cada vez mais concentrada; excludente, pois a participação do trabalhador está apenas na venda da sua força de trabalho e no recebimento de um salário, pois os trabalhadores não dispõem de condições para participar desse processo da mesma forma que as grandes empresas; e doloroso, pois, apesar de mudar a realidade de algumas pessoas, continua a concentrar a riqueza em um pequeno grupo, aprofundando desigualdades já existentes e criando novas desigualdades (Costa, 2006).

Segundo Delgado (2012b), a 'modernização conservadora' da agricultura significou a elevação do nível de investimentos de capital no campo, concentrando ainda mais a propriedade da terra no Brasil. Para Fernandes (2008), o agronegócio é o novo nome do modelo de desenvolvimento econômico da agropecuária capitalista. É uma tentativa de ocultar o caráter concentrador, predador, expropriatório e excludente para dar relevância somente ao caráter produtivista, da riqueza e das novas tecnologias. Em síntese, o agronegócio é a modernização que gera a exclusão pela produtividade, diz Canuto (2004).

O agronegócio promove maior concentração de terra e de renda, gera desemprego, emprega mão de obra escrava, alimenta a grilagem de terras, é responsável pelo aumento desenfreado do desmatamento da Amazônia e do Cerrado, traz efeitos perversos sobre a saúde humana e deixa atrás de si um rastro de conflitos e violência (Canuto, 2004).

A ocupação de extensas áreas por monoculturas, própria da produção do agronegócio, é responsável pelo desequilíbrio ecológico em territórios brasileiros. As altas taxas de produtividade repercutem na perda de biomassa dos biomas, com redução da cobertura vegetal nativa e consequente desequilíbrio dos ciclos biogeoquímicos, condições climáticas e perda da sociobiodiversidade (Soares e Porto, 2007).

O crescimento do uso dos insumos químicos, somado a outras ferramentas tecnológicas para a agricultura, ficou conhecido como a 'revolução verde'. No Brasil, segundo Moreira (2000), esse modelo - em particular nos anos 1960 e 1970 - veio atrelado ao subsídio de créditos agrícolas, às esferas agroindustriais, às empresas de maquinários e ao uso de agroquímicos (agrotóxicos e fertilizantes químicos), com a consolidação de uma agricultura de exportação. $\mathrm{O}$ aumento do uso de agrotóxicos se deveu também a uma política oficial de incentivo, reforçada, em 1975, pelo lançamento do Programa Nacional de Defensivos Agrícolas (PNDA). Assim, a vinculação entre a ampliação do crédito agrícola subsidiado e a compra de agroquímicos foi um dos principais instrumentos voltados para ampliar a difusão desses insumos no país. 
O modelo de escala de produtividade da agricultura não se justifica de forma central apenas pelo emprego dos agrotóxicos, mas, também, pelo melhoramento genético das plantas e pela crescente mecanização no campo. Observa-se que a transgenia especialmente voltada para a resistência de cultivos comerciais a herbicidas introduziu uma inovação no pacote tecnológico da agricultura por meio do casamento entre transgênicos e agrotóxicos. Isto significou a reprodução, em sua essência, do modus operandi da modernização conservadora da agricultura brasileira nos últimos trinta anos (Carneiro e Almeida, 2007).

No contexto da 'economia verde', a proposta de 'desenvolvimento' baseada na transgenia se apresenta como capaz de minimizar os efeitos ambientais nocivos da Revolução Verde. Mas trata-se de mais um engodo, posto que o agroquímico faz parte do pacote tecnológico, entre a semente geneticamente modificada e o agrotóxico para o qual é resistente. Sabe-se que a transgenia trouxe mais dependência econômica, interferência cultural, insegurança alimentar e poluição genética.

O agronegócio é responsável pelo uso em altíssima escala dos mais variados tipos de agrotóxicos. De 1978 a 1998, o consumo de herbicidas cresceu $540 \%$. Atualmente, os gastos com pesticidas agrícolas no Brasil superam os US\$2,7 bilhões por ano. Segundo a Empresa Brasileira de Pesquisa Agropecuária (Embrapa), em torno de $20 \%$ dos custos totais de produção da soja (R \$ 1.000/ha) são destinados a gastos com pesticidas (Canuto, 2004). O glifosato representa, sozinho, em torno de $40 \%$ do consumo de agrotóxicos no Brasil. Também se observa o fenômeno de resistência a esse veneno das plantas adventícias não desejadas, exigindo maior quantidade de sua aplicação. Além disso, no processo de colheita de soja transgênica são utilizados outros herbicidas extremamente tóxicos, como o paraquat, o diquat e o 2,4-D (Carneiro et al., 2015).

Ao condicionar o crédito rural à compra do agrotóxico, o Estado é o principal incentivador do pacote tecnológico que representa a 'modernidade' na agricultura, passando o mercado brasileiro a figurar entre os mais importantes para a indústria dos agrotóxicos. A reboque desse crescimento no consumo, cuja aquisição se dá, em sua maioria, via importação, muitas empresas multinacionais se instalaram no parque industrial das Regiões Sul e Sudeste desde o final da década de 1970.

Nesse cenário, o agronegócio tem se expandido no Nordeste do Brasil, centrado em monocultivos, e tem ensejado consequências sobre a produção agrícola associadas à exploração do trabalho de moradores e migrantes e à contaminação ambiental e humana, promovendo impactos à saúde, ocasionando mortes, intoxicações agudas e efeitos crônicos devido ao uso de agrotóxicos, dentre outros agravos (Rigotto, 2012). Ressalta-se que os efeitos dos agrotóxicos sobre a saúde podem ser de dois tipos: efeitos agudos, que 
são aqueles mais visíveis e que aparecem durante ou após o contato da pessoa com o produto e apresentam características bem marcantes, em geral, acometem mais os trabalhadores agrícolas; e efeitos crônicos, que podem aparecer semanas, meses, anos, ou até mesmo gerações após o período de uso ou contato com o produto contaminado, com efeitos carcinogênicos tanto para moradores do campo como da cidade.

O Brasil é tido com o maior consumidor desses venenos no planeta e a cada dia se torna mais dependente deles. Dito isso, questionamos qual o impacto que esse modelo do agronegócio tem sobre a saúde da população brasileira, sobretudo a saúde dos trabalhadores agrícolas?

\section{Procedimentos metodológicos}

Para a sistematização do número de casos de intoxicação por agrotóxicos no Nordeste e no país, utilizamos o banco de dados do Sistema Nacional de Informações Toxicofarmacológicas (Sinitox), 3 levantando o número total de casos por uso agrícola e por uso doméstico e óbitos entre os anos de 1999 e 2011, no Nordeste; além do grupo de intoxicação por agrotóxicos em geral no país no mesmo período. Foi utilizado o Excel $^{\mathrm{TM}} 2014$ na sistematização dos dados e construção dos gráficos.

Deve-se ressaltar, além dos dados evidenciados, que no Brasil há grande ocorrência de sub-registro das intoxicações por agrotóxicos. Esta é uma das grandes vulnerabilidades institucionais do país, entre outras relacionadas ao controle e monitoramento do uso de agrotóxicos em todo o território nacional, e um aspecto a ser levado em consideração nos processos de registro e reavaliação desses produtos técnicos, bem como nos estudos acadêmicos.

\section{Impactos à saúde devido aos agrotóxicos: trabalhadores agrícolas e consumidores no Nordeste brasileiro}

Os agrotóxicos reconhecidos cientificamente como danosos à saúde pública e ao meio ambiente, proibidos em diferentes países, continuam em circulação no Brasil. Segundo a Agência Nacional de Vigilância Sanitária (Anvisa), dos 50 agrotóxicos mais utilizados nas lavouras de nosso país, 22 são proibidos na União Europeia, fazendo do Brasil o maior consumidor de agrotóxicos já banidos por outros países. A questão dos agrotóxicos, filha da Revolução Verde nos tempos da Primavera silenciosa de Rachel Carson, reconfigura-se hoje no contexto da modernização agrícola conservadora, associada à reprodução do capital destrutivo e espoliador (Carneiro et al., 2014). 
Segundo o Ministério da Saúde, no Brasil, a cada ano, cerca de $500 \mathrm{mil}$ pessoas são contaminadas por agrotóxicos. Os brasileiros consomem alimentos com resíduos de agrotóxicos acima do limite permitido e ingerem substâncias tóxicas não autorizadas. Em outubro de 2013, a Anvisa revelou que $36 \%$ das amostras analisadas de frutas, verduras, legumes e cereais estavam impróprias para o consumo humano ou traziam substâncias proibidas no país, tendência crescente nos últimos anos. Estudo realizado sobre a produção de tomate industrial na região do submédio do vale do Rio São Francisco-Pernambuco mostrou que $11 \%$ das amostras estavam impróprias para consumo (Carneiro et al., 2014).

A soja é a principal cultura consumidora de agrotóxicos no Brasil, responsável por $38,5 \%$ do valor total das vendas em 2006, um aspecto preocupante, tendo em vista a expansão agrícola do país devido à soja transgênica. Em segundo lugar está a cana-de-açúcar com 12,6\% (Augusto et al., 2012), produto histórico do ciclo agrícola do Nordeste, desde os antigos engenhos às atuais indústrias e usinas de açúcar e etanol.

As evidências de estudos em saúde apontam que os agrotóxicos afetam a saúde dos consumidores de alimentos contaminados, moradores do entorno de áreas de produção agrícola ou de agrotóxicos, comunidades atingidas por resíduos de pulverização aérea e, majoritariamente, trabalhadores agrícolas expostos. Em relação ao processo de trabalho no modelo do agronegócio, Carneiro et al. (2014) destacam que dentre as causas apuradas de todos os Auxílios Doenças e Auxílios Acidentes concedidos pelo Instituto Nacional do Seguro Social (INSS) nos anos de 1999 e 2005, o maior percentual foram os advindos de lesões por envenenamento e consequências de causas externas, com 78,1\% em 1999 e 78,3\% em 2005.

No meio rural as morbidades prevalentes são as decorrentes de lesões do sistema osteomuscular e as lesões por envenenamento. Diversos autores discutem que a causa real das morbidades deve ser buscada nas condições de trabalho daqueles setores que hoje são sinônimos de 'modernidade técnica', ou seja, do agronegócio (Delgado, 2012a).

O Observatório de Saúde das Populações do Campo e da Floresta - OBTEIA (2014) destacou que, embora a incidência de acidentes no país envolvendo trabalhadores que realizam o cultivo de cana-de-açúcar esteja alta $(30,4 \%)$, a incidência de acidentes envolvendo trabalhadores do cultivo de laranja foi ainda mais alta, 32,7\%. O cultivo do fumo apresentou maior taxa de mortalidade e também maior taxa de letalidade, seguido pelo cultivo da uva. Esses são processos produtivos do agronegócio fortemente ancorados no uso de agrotóxicos.

Desse modo, a utilização de agrotóxicos no Brasil tem trazido sérias consequências, tanto para o meio ambiente como para a saúde da população, especialmente dos agricultores e a dos consumidores. Essas consequências são, 
na maioria das vezes, condicionadas pelo contexto e modo de produção químico dependente, pelas relações de trabalho, pela toxicidade dos produtos utilizados como agrotóxicos e de micronutrientes contaminados, precariedade dos mecanismos de vigilância da saúde, pelo uso inadequado ou falta de equipamentos de proteção coletiva e individual. Esta situação é agravada pelas precárias condições socioeconômicas e culturais da grande maioria dos trabalhadores rurais, o que amplia sua vulnerabilidade frente à toxicidade dos agrotóxicos.

No estado do Ceará, um estudo abordou dimensões da saúde dos trabalhadores e de saúde ambiental impactadas pelo processo de desterritorialização induzido pela modernização agrícola (Rigotto, 2011). O estudo investigou a contaminação da água para consumo humano, com base nas preocupações manifestadas pelas comunidades da Chapada do Apodi, nos municípios de Limoeiro do Norte e Quixeré. Identificou-se vários princípios ativos nas amostras de água, como o glifosato, a abamectina, o carbofurano, o endosulfan e o fosmete, todos agrotóxicos (Rigotto, 2011).

São numerosos os casos de contaminação ambiental resultantes da irresponsabilidade de empresas fabricantes e formuladoras de agrotóxicos, bem como do agronegócio, grande usuário desses venenos. Não raramente populações inteiras são expostas aos riscos da contaminação. As crianças são particularmente sensíveis aos agrotóxicos em decorrência da alta permeabilidade intestinal e do sistema de desintoxicação imaturo. Essas diferenças devem ser levadas em consideração ao avaliar riscos dos agrotóxicos.

Embora a pesquisa brasileira sobre o impacto do uso de agrotóxicos sobre a saúde humana também tenha crescido nos últimos anos, ainda é insuficiente para conhecer a extensão da carga química de exposição ocupacional e a dimensão dos danos à saúde, decorrentes do uso intensivo de agrotóxicos. Um dos problemas apontados é a falta de informações sobre o consumo de agrotóxicos e transgênicos e a insuficiência dos dados sobre intoxicações por estes produtos (Augusto et al., 2012).

Em relação ao Nordeste brasileiro, destacamos que na década de 2000 houve um crescimento expressivo do número de intoxicações por agrotóxicos, especialmente pelo uso agrícola, acompanhando o crescimento das intoxicações no Brasil, conforme sistematização dos Gráficos 1 e 2: 
Gráfico 1

Intoxicação humana por agrotóxicos, segundo ano. Nordeste do Brasil, 1999-2011

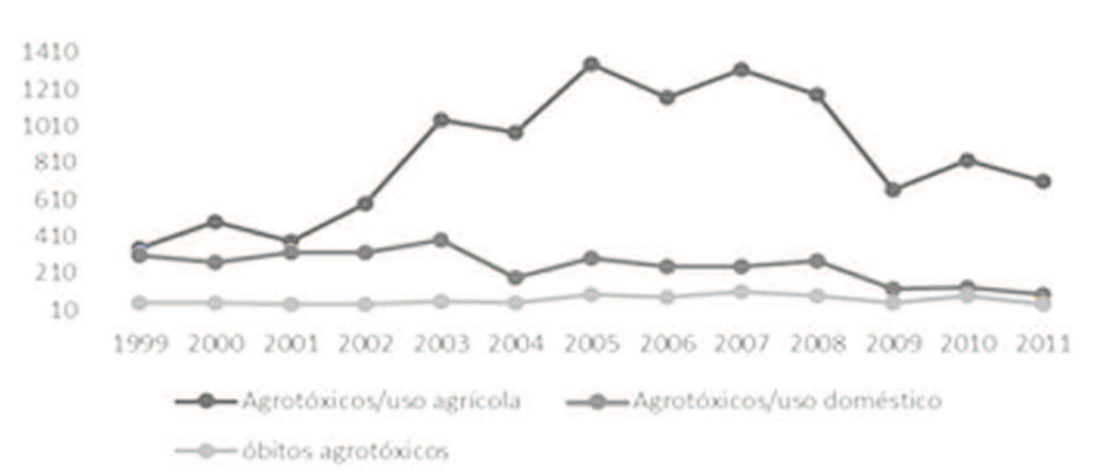

Fonte: Sistema Nacional de Informações Toxicofarmacológicas, 2005.

\section{Gráfico 2}

Intoxicação humana por agrotóxicos, segundo ano. Brasil, 1999-2011

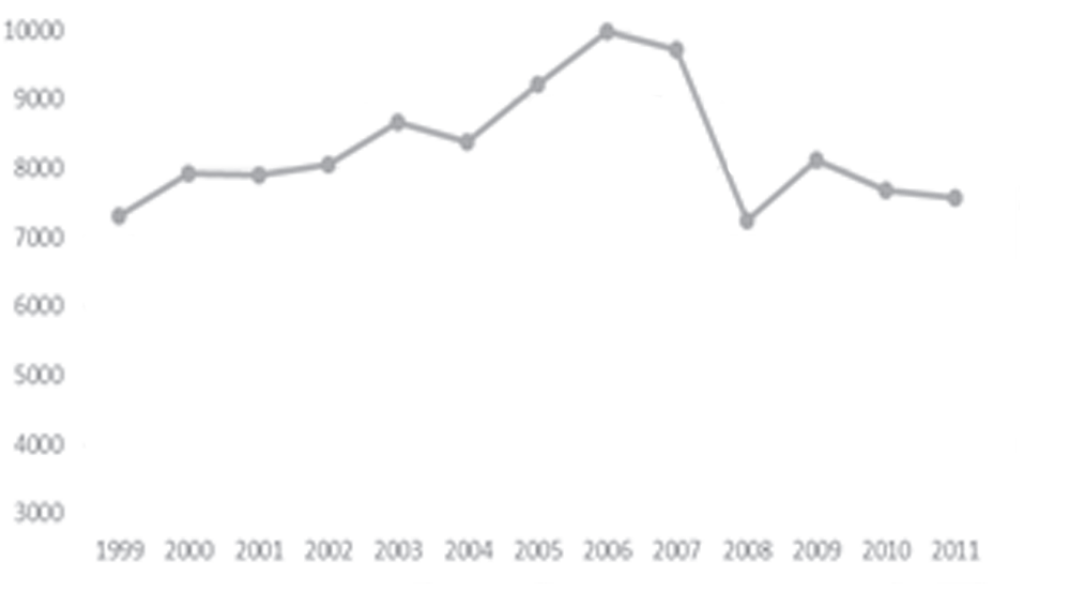

Fonte: Sistema Nacional de Informações Toxicofarmacológicas, 2005.

Em 2005 há um pico de casos de intoxicação por agrotóxicos, no caso do Nordeste mais de 1.200 casos. Essa região apresentou também a maior taxa de letalidade por intoxicação humana do país nesse ano: 6,89\% (1.349 casos e 93 óbitos) devido a intoxicação por agrotóxicos de uso agrícola. No Brasil, no mesmo ano, a letalidade foi de $3,23 \%$, e as demais regiões apresentaram: Norte, 3,23\%; Sudeste, 1,75\%; Centro-Oeste, 4,48\%; e Sul, 2,17\% (Sistema Nacional de Informações Toxicofarmacológicas, 2005). 
Podemos, desse modo, associar o crescimento da intoxicação por agrotóxicos na região Nordeste e no país ao crescimento nacional do agronegócio na última década, como demonstrado abaixo:

Gráfico 3

Saldo da balança comercial do Brasil (em US\$ bilhões)

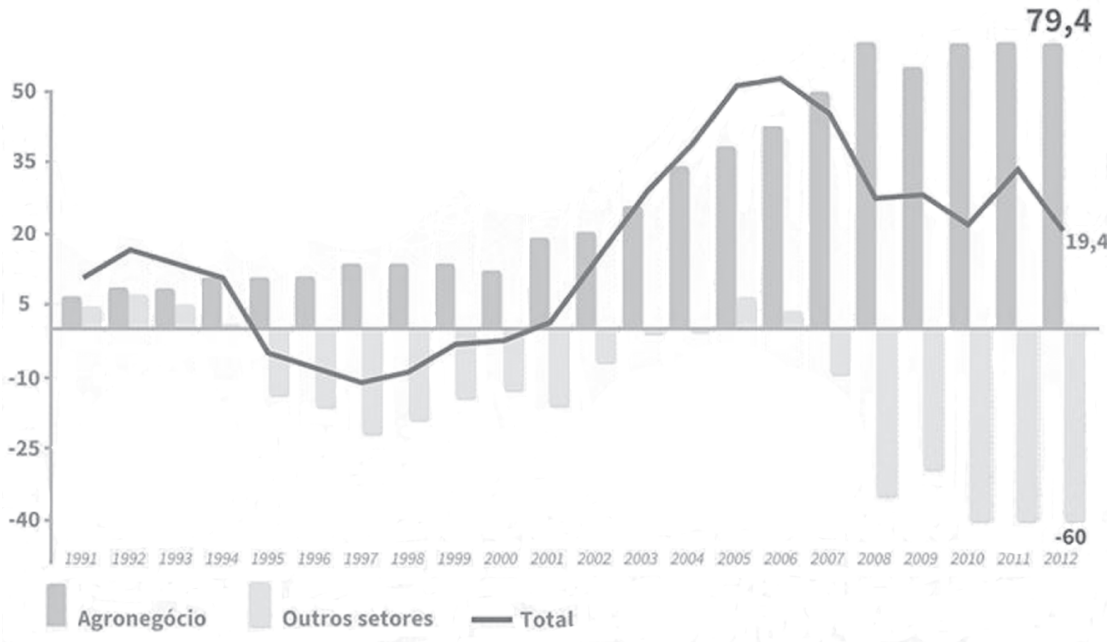

Fonte: Estatísticas de Comércio Exterior do Agonegócio Brasileiro (Agrostat). ${ }^{4}$

De fato, percebe-se que os picos produtivos de geração de superávit pelo agronegócio no Brasil nos anos 2005 e 2006 corresponderam ao pico de casos de intoxicação por agrotóxicos no Nordeste e no Brasil.

Nessa década, destaca-se a produção agrícola de cana-de-açúcar, frutas, cereais, leguminosas, oleaginosas no Nordeste, produtos para exportação sob o modelo agroexportador, associada ao uso intensivo de agrotóxicos e sementes transgênicas, a exemplo do milho, laranja, café.

Frente a essa situação, em que o Estado é forte para financiar o agronegócio e isentar os agrotóxicos de impostos, o mesmo Estado se comporta como frágil para proteger a saúde da população em termos de segurança alimentar e conservação da biodiversidade.

Desse modo, o cenário de saúde problemático exige medidas mitigadoras na utilização de agrotóxicos, a saber: limitação do uso de substâncias altamente tóxicas, regulação do mercado e da propaganda, desenvolvimento de produtos e tecnologias menos perigosas, inspeção dos produtos nas lojas de venda e do modo de uso nos locais de utilização, monitoramento da população mais exposta e mais vulnerável, atenção à saúde e amparo social, conscientização e capacitação dos trabalhadores rurais, dentre outras. 
Além disso, no Brasil a formação dos profissionais de saúde da rede básica e da média/alta complexidade é deficiente para fazer investigações das exposições humanas, de surtos de intoxicações e do diagnóstico de intoxicação aguda e crônica por agrotóxicos, de modo que há de se construir processos amplos de formação e capacitação no campo da saúde e o fomento ao registro/notificação dos casos nos sistemas de informação em saúde do Sistema Único de Saúde.

\section{Considerações finais}

Ao discutirmos o fortalecimento do agronegócio no país, compreendemos sua construção como um modelo de modernização conservadora em expansão em todo o território brasileiro e crescente no Nordeste, além de apreendermos a questão dos agrotóxicos e os impactos à saúde da população, com ênfase à saúde dos trabalhadores agrícolas. Destacamos que no Nordeste brasileiro houve maior taxa de letalidade por intoxicação a agrotóxicos de uso agrícola na última década, segundo os dados do Sinitox.

$\mathrm{Na}$ análise do modelo de modernização da agricultura brasileira, ancorado na lógica do capital financeiro, da produtividade espoliadora do ambiente, da apropriação da vida e de tecnologias, percebe-se como o Estado vem mantendo e fortalecendo os setores do agronegócio.

E também, ao mesmo tempo que o Estado brasileiro tem sido forte para liberalizar o uso de agrotóxicos, é frágil para monitorar e controlar seus danos à saúde e ao ambiente.

De todo modo, no contexto de medidas de proteção à saúde da população, destaca-se, recentemente, a aprovação em 2011 da Política Nacional de Saúde Integral das Populações do Campo e da Floresta, de relevância indiscutível, ao tratar da saúde da população vulnerável aos impactos advindos do agronegócio no Brasil, bem como outros processos, e do compromisso do SUS em desenvolver políticas de atenção à saúde desses grupos. Além disso, na dimensão da educação permanente, houve a criação, em 2015, do curso "Saúde das Populações do Campo, da Floresta e das Águas" ofertado pela Universidade Aberta do SUS (UNA-SUS), que dentre outros aspectos fomenta a capacitação de profissionais de saúde para a temática em debate.

\section{Colaboradores}

Os autores participaram integralmente na elaboração do manuscrito e aprovação final. 
Resumen Al considerar el contexto brasileño de aumento de la productividad agrícola asociado a los monocultivos, al agronegocio y al uso intensivo de agrotóxicos, diversas externalidades negativas emergen como impactos socioambientales y a la salud pública. El objetivo de este artículo es discutir el fortalecimiento del agronegocio en el país, comprendiendo su construcción como un modelo histórico de modernización en expansión en todo el territorio brasileño y creciente en el Nordeste. Además de ello, discurrir sobre el tema de los agrotóxicos y la salud, correlacionándolos a los casos de intoxicación humana. Con tal fin, desarrollamos un análisis del modelo de modernización apoyado en la tríada agronegocio, transgénicos y agrotóxicos, y discutimos los casos de intoxicaciones por agrotóxicos, a través de usos agrícola y doméstico, mediante la sistematización del banco de datos del Sistema Nacional de Informaciones Toxicofarmacológicas entre los años de 1999 y 2011 en el Nordeste. Observamos que en los últimos años el agronegocio se fortalece y el número de casos de intoxicación por agrotóxicos aumenta, destacándose la región Nordeste, que presenta los mayores índices de letalidad de intoxicación por agrotóxicos en Brasil, la que afecta principalmente a los trabajadores agrícolas.

Palabras clave intoxicación; letalidad; agroindustria; trabajadores rurales.

\section{Notas}

1 Universidade Federal do Rio Grande do Norte, Programa de Pós-Graduação em Saúde Coletiva, Natal, Rio Grande do Norte, Brasil.

$<$ isabellesaudelivre@hotmail.com>

Correspondência: Rua Lindolfo Gonçalves Chaves, 101, apto. 101, CEP 58021-200, Jardim São Paulo, João Pessoa, Paraíba, Brasil.

2 Universidade Federal do Rio Grande do Norte, Centro de Ciências da Saúde, Departamento de Odontologia, Natal, Rio Grande do Norte, Brasil.

$<$ roncalli@terra.com.br>

3 O Sistema Nacional de Informações Toxicofarmacológicas (Sinitox), criado em 1980 e vinculado à Fundação Oswaldo Cruz (Fiocruz), é responsável pela coleta, compilação, análise e divulgação dos casos de intoxicação e envenenamento registrados pela Rede Nacional de Centros de Informação e Assistência Toxicológica (Renaciat). O Sinitox considera, a partir de 1999, casos de intoxicação e envenenamento causados por 17 agentes tóxicos, categorizados em: agrotóxicos de uso agrícola, agrotóxicos de uso doméstico, produtos veterinários e raticidas.

4 Ver a respeito em: <www.agricultura.gov.br/internacional/indicadores-e-estatisticas/ balanca-comercial>. 


\section{Referências}

AUGUSTO, Lia et al. Dossiê Abrasco: um alerta sobre os impactos dos agrotóxicos na saúde. Rio de Janeiro: Abrasco, 2012.

BEZERRA, Juscelino. Agronegócio e a nova divisão social e territorial do trabalho agropecuário formal no Nordeste. 2008. $260 \mathrm{f}$. Dissertação (Mestrado em Geografia) - Universidade Estadual do Ceará, Fortaleza 2008.

CANUTO, Antônio. Agronegócio: a modernização conservadora que gera exclusão pela produtividade. Revista Nera, São Paulo, ano 7, n. 5, p.17-23, ago.-dez., 2004.

CARNEIRO, Fernando; ALMEIDA, Vicente. Os riscos socioambientais no contexto da modernização conservadora da agricultura. Ciência \& Saúde Coletiva, Rio de Janeiro, v. 12, n. 1, p. 20-24, 2007.

CARNEIRO, Fernando et al. Os impactos dos agrotóxicos na saúde, trabalho e ambiente no contexto do agronegócio no Brasil. Rio de Janeiro: Abrasco, 2014.

CARNEIRO, Fernando et al. Dossiê Abrasco: um alerta sobre os impactos dos agrotóxicos na saúde. Rio de Janeiro: EPSJV; São Paulo: Expressão Popular, 2015.

COSTA, Rosa. Modernização agrícola conservadora e as alterações socioespaciais no distrito de Lagoinha-Quixeré (CE). 2006. 74 f. Monografia (Especialização em Meio Ambiente) Universidade Estadual do Ceará, Limoeiro do Norte, 2006.

DELGADO, Guilherme. Do capital financeiro na agricultura à economia do agronegócio: mudanças cíclicas em meio século (1965-2012). Porto Alegre: Editora da UFRGS, 2012a.

DELGADO, Guilherme. Questão agrária e saúde Rio de Janeiro: Cebes, 2012b.

FERNANDES, Bernardo. Campesinato e agronegócio na América Latina: a questão agrária atual. São Paulo: Expressão Popular, 2008.

MOREIRA, Roberto. Críticas ambientalistas à revolução verde. Estudos Sociedade e Agricultura, Rio de Janeiro, n. 15, p. 31-34, 2000.
OBSERVATÓRIO DA POLÍTICA NACIONAL DE SAÚDE INTEGRAL DAS POPULAÇÕES DO CAMPO, DA FLORESTA E DAS ÁGUAS (OBTEIA). Relatório preliminar da análise de dados secundários: 2014. Teia de ecologia de saberes e prática. Disponível em: <www. saudecampofloresta.unb.br/wp-content/ uploads $/ 2015 / 03 /$ Relato $\%$ CC $\% 81$ rio-Dados-secund $\%$ C $3 \%$ Alrios-finall.pdf $>$. Acesso em: 18 abr. 2015.

PORTO, Marcelo; SOARES, Wagner. Modelo de desenvolvimento, agrotóxicos e saúde: um panorama da realidade agrícola brasileira e propostas para uma agenda de pesquisa inovadora. Revista Brasileira de Saúde Ocupacional, São Paulo, v. 37, n. 125, p. 46-49, 2012.

RIGOTTO, Raquel. Agrotóxicos, trabalho e saúde: vulnerabilidades, resistência no contexto da modernização agrícola no Baixo Jaguaribe/CE. Fortaleza: Edições UFC; São Paulo: Expressão Popular, 2011.

RIGOTTO, Raquel et al. O verde da economia do campo: desafios à pesquisa e às políticas públicas para a promoçao da saúde no avanço da modernizaçao agrícola. Ciência \& Saúde Coletiva, Rio de Janeiro, v. 17, n. 6, p. 1.533-1.542, 2012.

SANTOS, Boaventura S.; CHAUÍ, Marilena. Direitos humanos, democracia e desenvolvimento. São Paulo: Editora Cortez, 2013.

SISTEMA NACIONAL DE INFORMAÇÕES TOXICOFARMACOLÓGICAS (Sinitox). 2005. Disponível em: <http://sinitox.icict.fiocruz. br/sites/sinitox.icict.fiocruz.br/files//tab02_ brasil_2005.pdf>. Acesso em: 5 out. 2014.

SOARES, Wagner; PORTO, Marcelo. Atividade agrícola e externalidade ambiental: uma análise a partir do uso de agrotóxicos no cerrado brasileiro. Ciência \& Saúde Coletiva, Rio de Janeiro, v. 12, n. 1, p. 38-43, 2007.

Recebido em 05/06/2015

Aprovado em 14/07/2015 